\title{
Practical tips on interviewing the great and the good
}

\author{
Barbara Buckley Owen
}

\begin{abstract}
Based on experience of researching for a $\mathrm{PhD}$ and many years working in information policy, this article provides practical tips to guide anyone wishing to interview experts as part of their research. It takes a common-sense approach to the whole process, starting with the initial decisions to be made, types of interviews, how to get your interviewees on board, prioritisation of interviewees, venues and timing. It then takes you through recording and managing the interviews, and finally covers transcription and wrapping up. The need for careful planning and flexibility are stressed. A checklist of 42 tips to help you plan your interviews is appended.
\end{abstract}

\section{Introduction}

If you need to interview experts as part of your research, the textbooks will give you advice on all sorts of ethical and methodological concerns (e.g. Bogner, Littig and Menz (2009) and Silverman (2005)) but they are not necessarily in the market for giving practical tips on how to go about it. Based on experience of interviewing senior civil servants, advisers, academics and practitioners for a $\mathrm{PhD}$ in government information policy - and over many years previously as a policy adviser - here is a practical guide to interviewing the great and the good. Most of it is common sense and obvious, but hopefully it is helpful to bring the ideas together. Appended to the article is a checklist of tips, based on my experience (Appendix 1).

\section{Before}

\subsection{Why you are interviewing}

One of the first considerations is why you are interviewing particular individuals. Is it for their expertise, their experience or their influence? That will affect what you want to get out of the interviews and therefore how you approach the potential interviewees. A related question is whether you want the interviews to

\section{Author}

Barbara Buckley Owen recently obtained her PhD from Loughborough University, having spent 25 years working in information policy, research support, product development and library cooperation.

Email: barbara.buckleyowen@ virgin.net. 
be on or off the record. For example, if you are interviewing for someone's expertise, there may be lots of other people with equivalent know-how who would do just as well. However, you may want to interview particularly influential individuals and being able to lend your research their imprimatur would add valuable credibility to your findings.

You will find it helpful to devise a short paragraph describing your research and tailored to each potential interviewee to explain why their input is desired. You can then use this in face-to-face, letter or email contact. If you have learnt it, you will find it helpful when you suddenly find yourself confronted with a suitable person, say at a conference or meeting.

\subsection{Channel of communication}

Before the formal approach, you need to decide how you would prefer to conduct the interview, although the final decision will have to be what suits the interviewee. Face-to-face interviewing gives you both oral and visual signals in combination. It may be easier to build a rapport with the interviewee if you don't already know them, but face-to-face interviews are time-consuming and logistically take more arranging. Telephone interviews may take less time and save you the travelling costs, but they don't give you the benefits of face-to-face interviews; however, if the interviewee is abroad this may be the sensible compromise. Email correspondence can be easier for the interviewee if they are busy. You also get considered, probably shorter, answers that don't need transcription. On the other hand, it may be difficult to ask supplementary questions or get as much detail as you would like. Also, your questions must be very clear and unambiguous to make sure they are not misinterpreted.

\subsection{Interview questions}

There are three basic types of interviews: structured, semi-structured and open. You may want to use one type or a mixture. Some open interviews at the start can help you refine your research questions. You will probably want to begin with a standard set of questions that you can ask everyone and then adapt them to each interviewee as appropriate, but you may also find it helpful to have supplementary questions to probe further as required. I found it useful to have these in a tabular format: I had one column for main questions and another for supplementary questions, which I amended for each person. Work out how long you would ideally like to spend on each question and prioritise them, with nominal times against each. All this information can go on the table and provide a guide during the interview. Particularly if you are an inexperienced interviewer, it is helpful to run pilots at this stage to see if your interview schedule delivers answers to what you are trying to find out.

\subsection{Interviewees}

In drawing up your potential list of interviewees, decide how many people you want to interview and identify at least twice that number to allow for their lack of availability or unwillingness. It is helpful to prioritise your interviewees (for example $1=$ top priority, must have if possible; 2 = a good substitute if the top 
priority is unavailable; $3=$ would do to provide balance but they could drop off the list if someone more appropriate were identified), as this can help you decide in which order you want to approach people. You may find that other interviewees get suggested along the way - the snowball effect - so this prioritisation can be fluid.

\subsection{Getting your interviewees on board}

Don't be tempted to start interviewing straight away if you are new to the subject; know your subject as thoroughly as possible before you start approaching individuals. This will give you confidence and will in turn give your interviewees confidence that it is worth their while participating.

If you don't know interviewees personally, an ideal way to meet them is to go to where they are and introduce yourself, e.g. when they are speaking at an event or attending a meeting. You may only have thirty seconds if you are in a queue so have your own business card ready, get their contact details and follow up straight away. Tailor your introduction to why they, specifically, are vital for your research.

If it is not possible to meet your target interviewee, get a personal recommendation from someone you both know or arrange for someone senior to you to intervene on your behalf. Saying who else you have already interviewed can also lend credibility, provided that those people have agreed to go on the record. Go through a personal assistant if necessary: they can be blockers but can also be unblockers.

\subsection{Venue}

If you are interviewing face-to-face you need to organise the venue for the discussion. The interviewee's office or a meeting room works best, assuming they have one and allow access. Avoid cafés, especially ones with lots of hard surfaces, as they are very noisy and you can't stop people sitting near you - even if your microphone is on its least sensitive setting, you will pick up lots of background sounds. If this is not possible, don't order anything which might leave you worrying about whether you have a "moustache", such as a cappuccino or thick hot chocolate (learnt from experience!), or a green salad that might leave bits on your teeth - minimise distractions. Have your own suggestions for somewhere quiet - try out some locations in advance. If you are based in London, the foyer of the Royal National Theatre is quite good as it has various corners away from the coffee bar and free wi-fi as well.

\section{7 $\quad$ Timing}

Allow plenty of time for planning. However much time you allow to set up your interviews, it will take longer than you expect. The great and good are busy people so you have to assume you might not be able to get an appointment for three months.

Preferably don't schedule more than one interview a day. If this is not possible, leave plenty of time in between and allow yourself a chance to relax as interviewing can be very tiring. Build in time for transcribing between interviews 
so that you don't get behind with this. Finally don't book an interview immediately after you are due to return from holiday in case you are delayed travelling back; the delay can be stressful enough without worrying about missing an appointment that has taken months to set up.

\section{During}

\subsection{Recording}

Technology can let you down at the most embarrassing moments so take two digital recording devices. Check that they both work at the start and put in new batteries; it's less hassle than risking failure during the recording and you will probably be so engrossed that you may not notice if they stop working. Before you start the machines you will need agreement to record the interview, as well as clarifying whether it is on or off the record and if there are any conditions attached. It is also helpful to confirm how long the interview will last as the interviewee may have more or less time than originally planned when the interview was set up.

\subsection{Managing the interview}

Keep your own speech to a minimum and especially try not to make noises of agreement and encouragement that can drown out the recording. However, you need to keep control. The great and the good may be opinionated and go off at tangents so you need to know your subject well enough to gauge whether - and how - to bring them back to your agenda or to respond to theirs.

Keep track of timing, using your pre-determined schedule. You will need to adapt the order of questioning if the interview raises something earlier than you planned to ask about it or if you are running short of time. If the interviewee is interested, however, they may give you more time than they originally intended, so be prepared for this. Having supplementary questions can help here. Above all, build in flexibility and expect the unexpected.

\section{After}

\subsection{Immediate action}

Send a thank-you email straight away, reminding the interviewee of anything they promised. This is not just good manners - you may get a response of "Don't hesitate to get back to me if I can help further" - giving you an entrée to do just that in the future. Make copies of your recording straight away in several places, including emailing it back to base if you are away travelling.

\subsection{Transcription}

If you are doing the transcription yourself, allow at least five times as long as the interview. The text may be very dense with little you can leave out. Expect around 6000 spoken words in an hour as a rough guide. It is best to do the transcription as quickly as possible after the interview while it is fresh in your mind; the longer you leave it the more of a burden it seems to become. 


\subsection{Wrapping up}

Get approval for use of specific quotes from your interviewees if that was agreed in principle at the interview and send findings/recommendations/conclusions to any interviewee that requested them or showed sufficient interest.

This article is based on a paper given at the AHRC-funded Research Methods Forum at Loughborough University, 8-9 July 2010. It is mostly common sense but reflects lessons that have been learned from experience. Things can, and do, go wrong, but with careful planning you can cope with the unexpected. Hopefully your interviewing will be a trouble-free and rewarding experience, and above all, enjoyable.

\section{Further reading}

Gillham's (2000) The research interview includes a chapter on 'Organising and managing the interview', whilst Robson (2002) and Denscombe (2007) also each provide useful chapters on interviewing as part of the research process. Robson himself recommends Kvale (1996) and Weiss (1994) as good general textbooks on interviewing. The above do not focus on interviewing experts, however Bogner, Littig and Menz (2009) do address interviewing the great and the good in some detail, although not at the practical level. You may also find Harvey (2011) useful for guidance on managing interviews with the elite.

\section{References}

Bogner, A., Littig, B. and Menz, W. (eds.) (2009) Interviewing experts. Basingstoke: Palgrave Macmillan.

Denscombe, M. (2007) The good research guide: for small-scale social research projects. $3^{\text {rd }}$ ed. Maidenhead: Open University Press.

Gillham, B. (2000) The research interview (Real World Research). London: Continuum International Publishing.

Harvey, W.S. (2011) Strategies for conducting elite interviews, Qualitative Research, 11(4), 431-444.

Kvale, S. (1996) InterViews: an introduction to qualitative research interviewing. Thousand Oaks: Sage.

Kvale S. and Brinkmann, S. (2008) InterViews: learning the craft of qualitative research interviewing. $2^{\text {nd }}$ ed. London: Sage.

Robson, C. (2002) Real world research. Oxford: Blackwell Publishers.

Weiss, R. (1994) Learning from strangers: the art and method of qualitative interview studies. New York: Free Press. [Kindle edition 2008.] 


\section{Appendix 1: Forty-two answers to everything you need to know about interviewing the great and the good}

\section{Before}

Why you are interviewing

\section{Channel of communication}

\section{Interview questions}

Interviewees
1. Decide if you are interviewing people for their expertise, their experience or their influence.

2. Decide whether you want the interviews to be on or off the record.

3. Devise a short paragraph to describe your research and why you need their input, to use in face to face contact and/or letter/email - and learn it.

4. Decide your preferred method of communication for the interview. You may have to use other methods as a fall-back position.

5. Interviewing face-to-face gives you both oral and visual signals in combination. In this way it may be easier to build a rapport with the interviewee if you don't already know them.

6. Telephone interviews may take less time and may therefore be the preferred choice of the interviewee. They also save you travelling time and money, however you don't get the above benefits of face-to-face interviews.

7. Email correspondence can be easier for the interviewee if they are busy. You also get considered, probably shorter, answers that don't need transcription. However it may be difficult to ask supplementary questions or get as much detail as you would like. Your questions must be very clear and unambiguous to make sure they can't be misinterpreted.

8. Decide what type of interview/s to use: structured, semistructured, open.

9. Some open interviews at the start can help refine the research questions.

10. Devise standard questions that you can adapt for each interviewee.

11. Have supplementary questions you can ask if you want to probe further.

12. Work out how long you ideally need to ask your questions. Prioritise questions and put nominal times against each one: this may vary between interviews.

13. Run pilot interviews, especially if you are inexperienced at interviewing.

14. Decide how many people you need to interview and identify double that number. The list may evolve as other people are suggested in the course of the interviews - the snowball effect.

15. Prioritise them by their importance to your research and by appropriate order of approach. 
Getting your interviewees on board

Venue

Timing

\section{During}

Recording

\section{Managing the interview}

16. Learn your subject very well before approaching interviewees so that you can do so with confidence. Interviewees can then have confidence in you and believe that it's worth their while participating.

17. If you don't know interviewees personally, ideally go to where they are and introduce yourself e.g. when they are speaking at an event or attending a meeting. Have your own business card ready, get their contact details and follow up straight away.

18. If this is not possible, get a personal recommendation from someone you both know or arrange for someone senior to you to intervene on your behalf.

19. Saying who else you have already interviewed can lend credibility, provided that those people have agreed to go on the record.

20. Go through a PA if necessary: they can be blockers but can also be unblockers.

21. The interviewee's office or a meeting room works best assuming they have one and allow access.

22. Avoid cafés as they are very noisy and you can't stop people sitting near you. If this is not possible, don't order anything which might leave your worrying about whether you have a "moustache" - minimise distractions.

23. Have your own suggestions for somewhere quiet - try out some in advance.

24. Allow plenty of time for planning - this will take longer than you expect.

25. The great and good are busy people so you have to assume you might not be able to get an appointment for 3 months.

26. Preferably don't schedule more than one interview a day. If this is not possible, leave plenty of time in between. Build in time for transcribing between interviews so that you don't get behind with this.

27. Don't book an interview immediately after you are due to return from holiday in case you are delayed travelling back. 
Managing the interview (cont.)
33. You need to keep control. The great and the good may be opinionated and go off at tangents. You must know your subject well enough to gauge whether to, and how to, bring them back to your agenda or to respond to theirs.

34. Keep track of timing, using your pre-determined schedule.

35. Be flexible in the order of questioning if the interview raises something earlier than you planned to ask about it or if you are running short of time.

36. If the interviewee is interested, they may give you more time than they originally intended, so be prepared for this.

After

Immediate action

Transcription

Wrapping up
37. Send a thank-you email straight away, reminding the interviewee of anything they promised. This is not just good manners - you may get a response of "Don't hesitate to get back to me if I can help further" - giving you an entrée to do just that in the future.

38. Make copies of your recording straight away in several places, including emailing it back to base if you are away travelling.

39. If you are doing the transcription yourself, allow at least 5 times as long as the interview. The text may be very dense with little you can leave out. Expect around 6000 spoken words in an hour as a rough guide.

40. Transcription should be done as quickly as possible after the interview while it is fresh in your mind.

41. Get approval for use of quotes if that was agreed at the interview.

42. Send findings/recommendations/conclusions to any interviewee who requested them or showed sufficient interest.

\section{Acknowledgement}

Barbara Buckley Owen's PhD at Loughborough University, Department of Information Science, was funded through an AHRC studentship.

\section{Open access and copyright}

Library and Information Research is an open access journal. A freely available copy of this paper may be downloaded from the journal's website: http://www.cilipjournals.org.uk/lir

Copyright and associated moral rights in works published in Library and Information Research are retained by the author(s) but this paper may be used freely, with proper attribution, in educational and other non-commercial settings. 